\title{
Frequency Speed Control of Rotary Travelling Wave Ultrasonic Motor Using Fuzzy Controller
}

\author{
Fatima Zohra Kebbab \\ Department of Electrical Engineering \\ Laboratory DAC HR \\ Ferhat Abbas University Setif I, Algeria \\ fatimazohra.kebbab@univ-setif.dz \\ Dalel Jabri \\ Department of Electrical Engineering \\ Laboratory DAC HR \\ Ferhat Abbas University Setif I, Algeria \\ dalel.jabri@yahoo.fr
}

\author{
Djamel Eddine Chouaib Belkhiat \\ Department of Physics \\ Laboratory DAC HR \\ Ferhat Abbas University Setif I, Algeria \\ djamel.belkhiat@univ-setif.dz \\ Saâd Belkhiat \\ Department of Electrical Engineering \\ Laboratory DAC HR \\ Ferhat Abbas University Setif I, Algeria \\ belsa_set@yahoo.fr
}

\begin{abstract}
This paper proposes frequency speed control of rotary travelling wave ultrasonic motor (TWUSM), type Daimler Benz AWM90-X motor. The control characteristics of TWUSM are complicated, highly nonlinear and varying in time. This can lead to deterioration of the performance of conventional controller such as proportional integral (PI). In order to achieve high control performance of the TWUSM, fuzzy logic controller (FLC) has been designed and compared to the conventional PI controller. To validate the performance of the proposed FLC, simulation of the speed response has been performed and analyzed for a varying load. The simulation results show that the FLC has smaller settling time, smaller rising time and minimum error in steady state. Furthermore, the fuzzy controller provides good results for large load variations. The frequency output of the controller has been validated with experimental measurements of AWM90-X.
\end{abstract}

Keywords-nonlinear control; fuzzy logic controller; travelling wave ultrasonic motor type Daimler-Benz; AWM90-X

\section{INTRODUCTION}

TWUSMs have structural and operational advantages compared to conventional electromagnetic motors, such as compact size, lighter weight, very low speed operation, high torque, nonmagnetic operation, freedom of constructional design, very low inertia, high speed response, possibility of electromagnetic noise reduction and miniaturization [1]. Moreover, the settling time in ultrasonic motors is very short, fast response is one of the most important TWUSM advantages, which makes it suitable for applications with fast response demands such as robot actuators and auto-focus cameras. Several types of ultrasonic motors have been suggested and designed in the last 25 years [2]. Their operating principle is based on piezoelectric vibrations that convert electric energy to mechanical energy in the form of elastic vibrations [3]. It consists of two basic parts: the stator with piezoelectric ceramics, and the driven part (rotor). Apart from the advantages of TWUSM, deriving mathematical model for TWUSMs is a difficult task due to their complicated and highly nonlinear characteristics. In addition, the dynamic speed characteristics of TWUSM are time-varying due to the increase in temperature and depend on operating conditions such as driving frequency, source voltage and load torque [4, 5].

The speed control of TWUSMs is one of the important issues under consideration [5-7]. Three kinds of speed control strategies exist in the literature. The TWUSM speed can be controlled by the driving frequency, the phase difference or the voltage amplitude of the two excitation sinusoidal voltage of TWUSM. However, aimed at these problems, several researchers have opted for the driving frequency of the sinusoidal voltage as control variable [6-8]. There is no perfect control scheme for TWUSMs. The ultrasonic motor speed controllers belong to several conventional and numeric controller types. A speed tracking control system using both neuro-fuzzy control and direct pulse width modulation for TWUSM has been developed in [8]. In the same way, authors in [9] used also a fuzzy neural network controller. Authors in $[4,10,11]$ studied a servo speed control system for travelingwave ultrasonic motor [4] and a servo position control for TWUSM [10] where fuzzy neural network was the control tool [11]. Authors in [12] proposed a position control scheme for TWUSMs. Authors in [13] used $H \infty$ strategy to control rotary travelling wave ultrasonic motor TWUSM while authors in [14] proposed an intelligent PID speed controller of TWUSM. In a nutshell, most of developed works for ultrasonic motors control focused on a motor of USR60 type. However, the speed control for Daimler-Benz AWM90-X motor has rarely been explored so far, which motivated us to make this study as a continuation of our previous works [15-17]. The main contribution of this work consists to the design of a fuzzy logic controller to drive the speed of the Daimler-Benz AWM90-X motor. The robustness of the proposed controller against load 
variation is verified in this paper. Moreover, a deep comparative study, between performances obtained by using FLC and those obtained by a conventional PI controller, is performed in this paper. Finally, the frequency output of FLC has been validated with experimental measurements of AWM90-X.

\section{MATHEMATICAL MODEL}

\section{A. Basic Assumptions}

The structure and driving mechanism of TWUSM are special. They include many nonlinear and uncertain factors, and the whole drive course is very complicated [15-17]. In order to simplify the model of TWUSM, the following assumptions must be made:

- The rotor is a rigid body, its surface is smooth.

- The friction material is visco-elastic, its surface is smooth, neglecting the influence of surface roughness.

- The surface of stator teeth is continuous sinusoidal wave, neglecting the influence of tooth space.

- Coulomb friction law is valid on the contact interface between stator and rotor.

- The friction layer is divided into tangential and normal system independently, which do not influence each other.

\section{B. Model Structure of The Travelling Wave Ultrasonic Motor}

The model of the motor is structured as illustrated in Figure 1. The model of the travelling wave motor consists of four main modules: Voltage source, stator with piezoelectric ceramic, stator-rotor interface and rotor.

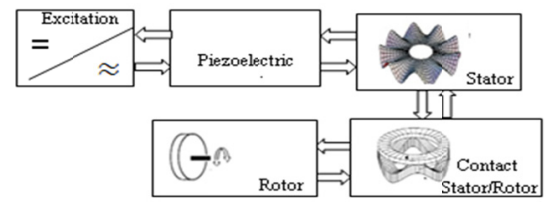

Fig. 1. Functional diagram of the travelling wave ultrasonic motor

\section{Model of the Stator}

Stator is the most important part in the travelling wave ultrasonic motor. The piezoelectric ceramic placed below the stator generates two orthogonal modes of vibration, the superposition of which generates a progressive wave. The stator ensures an electromechanical energy conversion. We note that the stator of a piezoelectric ultrasonic motor can be presented as a piezoelectric actuator. The equivalent model illustrated in Figure 2, represents the behavior of a two excitation system.

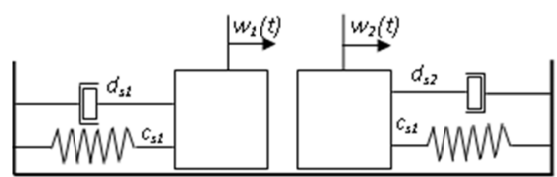

Fig. 2. Equivalent mechanical model of the stator

Equations (1) and (2) describe the dynamics of the two excitation system:

$$
\begin{aligned}
& m_{e f f} \ddot{w}_{1}+d_{S 1} \dot{w}_{1}+c_{S 1} w_{1}=A_{1}\left[\left(1-\varepsilon_{1}\right) U_{P 1}+\varepsilon_{2} U_{P 2}\right]+F_{S 1} \\
& m_{e f f} \ddot{w}_{2}+d_{S 2} \dot{w}_{2}+c_{S 2} w_{2}=A_{2}\left[\left(1-\varepsilon_{2}\right) U_{P 2}+\varepsilon_{1} U_{P 1}\right]+F_{S 2}
\end{aligned}
$$

where $m_{\text {eff }}=$ stator mass, $c_{S 1}, c_{S 2}=$ equivalent rigidity of the stator, $d_{S 1}, d_{S 2}=$ damping, $A_{1}, A_{2}=$ force factor of piezoelectric ceramics, $w_{1}, \quad w_{2}=$ deformation amplitude of the two modes, $U_{P 1}$, $U_{P 2}=$ phases voltage and $F_{S 1}, F_{S 2}=$ external modal forces.

The superposition of the two standing waves creates the traveling wave:

$$
w\left(x^{\prime}, t\right)=w_{1}(t) \sin \left(k x^{\prime}\right)+w_{2}(\mathrm{t}) \cos \left(k x^{\prime}\right)
$$

where $k=2 \pi / \lambda$ is the wave number and $\lambda$ is the wave length of the mode. The point displacement on the stator surface is moving on elliptical locus:

$$
\vec{w}_{\varphi}\left(x^{\prime}, t\right)=w\left(x^{\prime}, t\right) \vec{u}_{z}-a \frac{\partial}{\partial x^{\prime}} w\left(x^{\prime}, t\right) \vec{u}_{x^{\prime}}
$$

The tangential speed of this point:

$$
v_{t}\left(x^{\prime}, t\right)=-a \frac{\partial}{\partial t}\left(\frac{\partial}{\partial x^{\prime}} w\left(x^{\prime}, t\right)\right)
$$

\section{Modeling of Stator-Rotor Interface}

Stator-rotor interface model is the most complex part of the whole model of the ultrasonic motor. Equations (6) and (7) describe the traveling wave and tangential speed.

$$
\begin{gathered}
w\left(x^{\prime}, t\right)=\hat{w} \cos \left(k x^{\prime}-\omega t\right) \\
V_{t}\left(x^{\prime}, t\right)=\hat{V}_{t} \cos \left(k x^{\prime}-\omega t\right)
\end{gathered}
$$

where $\omega=2 \pi f$ and $f$ is the resonance frequency. The modeling of the mechanical contact between the stator and the rotor with the reference linked to the stator $\left(x^{\prime}\right)$ is not effective. It turns out to be useful to introduce a new coordinate system moving with the travelling wave, i.e. moving according to the inertial coordinate system with the speed and direction of the travelling wave: $x=x^{\prime}-(\omega / k) \cdot t$, we can express (6) and (7) as:

$$
\begin{aligned}
& w(x)=\hat{w} \cos (k x) \\
& V_{t}(x)=\hat{V}_{t} \cos (k x)
\end{aligned}
$$

A figure of the contact mechanism between stator and rotor for a peak of the traveling wave can be seen in [16]. In such a scheme, $x_{k}$ is half of the contact zone length, $x_{l}$ and $x_{r}$ are the points of the stator which have the same tangential speed with the rotor.

$$
x_{k}=\frac{1}{k} a \cos \left(\frac{w_{R}-\hat{w}}{\hat{w}}\right)
$$

In the contact zone $\left(-x_{k} \leq x \leq x_{k}\right)$, interpenetrating of stator into the contact layer causes the creation of normal 
contact pressure along the contact zone. The overlap between stator and rotor is given by (11).

$$
\Delta w=\hat{w}\left(\cos k x-\cos k x_{k}\right)
$$

Line force distribution along the contact region can be expressed by (12).

$$
f(x)=C_{N} \hat{w}\left(\cos k x-\cos k x_{k}\right)
$$

where $C_{N}$ is the equivalent stiffness of the contact layer. The frictional force can now be calculated as in (13) and the axial force is described in (14):

$$
\begin{aligned}
& F=n \mu \int_{-x_{k}}^{x_{k}} \operatorname{sgn}\left(V_{t}(x)-V_{\text {rotor }}\right) f(x) d x \\
& F_{\text {norm }}=n \int_{-x_{k}}^{x_{k}} f(x) d x
\end{aligned}
$$

where $\mu$ is the dynamic coefficient of friction. $n$ is the number of wave crests. The maximal motor torque $T$ is :

$$
T=\mu \cdot R_{m} \cdot F_{\text {norm }}
$$

where $R_{m}$ is the effective radius of the contact.

\section{E. Modeling of the Rotor Dynamic}

Rotor of travelling wave ultrasonic motor is modeled to have two degrees of freedom: vertical motion and rotation. Equations (16) and (17) describe the rotational and vertical motion of the rotor.

$$
\begin{aligned}
& J \dot{\omega}_{\text {rotor }}=T-T_{\text {load }} \\
& m_{\text {rotor }} \ddot{w}_{R}+d_{\text {rotor }} \ddot{w}_{R}+c_{\text {rotor }} w_{R}=F_{n}-F_{\text {norm }}
\end{aligned}
$$

where $J$ is the inertia of the rotor, $\omega_{\text {rotor }}$ is the angular velocity of the rotor, $T_{\text {load }}$ is the load torque, $m_{\text {rotor }}$ is the equivalent mass of the rotor, $d_{\text {rotor }}$ is the equivalent damping, $c_{\text {rotor }}$ is the equivalent stiffness and $F_{\text {norm }}$ is the the axial applied force.

Normal force acting on the rotor is :

$$
F_{n}=n \int_{-x_{k}}^{x_{k}} f(x) d x
$$

\section{F. Energy Conversion}

Figure 3 shows the speed-frequency characteristics of the TWUSM under different load torques. When the load torque increases, the speed of the motor decreases the speedfrequency characteristic of the USM.

\section{PI SPEED CONTROLLER}

The model of the speed of TWUSM actuator is represented in a simplified block diagram in Figure $4 . y_{m}(k)$ is the commanded speed, $y(k)$ is the rotor speed, $e(k)$ is the speed error, and $u(k)$ is the control signal (driving frequency). The control input for the PI controller is determined by:

$$
u(k)=K_{P} e(k)+T_{s} K_{I} \sum_{n=0}^{k} e(n)
$$

$K_{P}$ and $K_{T}$ are proportional and integral gains in the PI controller and $T_{S}$ denotes the sampling period. PI gain values are given in the Table I.

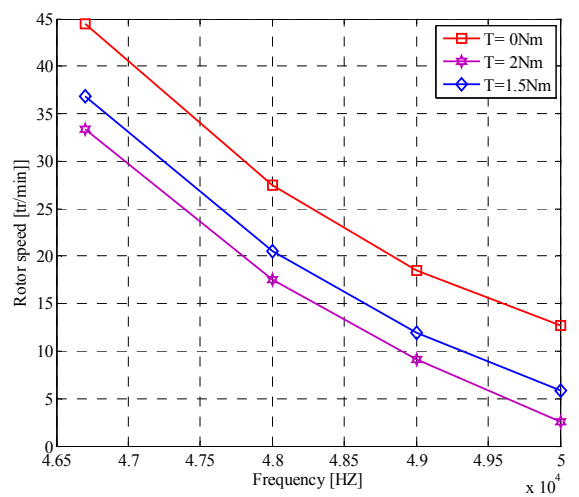

Fig. 3. Speed-frequency characteristics of USM for different load torques.

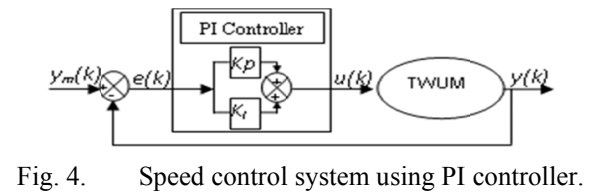

TABLE I. PI CONTROLLER VALUES.

\begin{tabular}{|c|c|c|}
\hline $\begin{array}{c}\text { Gain coefficient } \\
\text { Values }\end{array}$ & $K_{P}$ & $K_{T}$ \\
\cline { 2 - 3 } & 0.02 & 100 \\
\hline
\end{tabular}

\section{SPEED CONTROL USING FUZZY LOGIC CONTROLLER}

Fuzzy logic controller is a rule-based controller. Fuzzy logic enables the designer to describe the general behavior of the system in a linguistic manner by forming IF-THEN rules [19]. The design steps are: 1) defining inputs, output and universe of discourse, 2) defining fuzzy membership functions and rules. A fuzzy logic control block diagram [21] can be seen in Figure 5. To define fuzzy membership function, we can choose different shapes based on experience. The triangular and trapezoidal shapes are very used because they are easy to represent designer's ideas and require less computation time. The performance of the controller can be improved by adjusting membership function and rules. Otherwise, the fuzzy output is converted into real value output i.e. crisp output by the process called defuzzification. Even though many defuzzification methods are available, the most preferred one is the centroid method that requires less computation time [22]. The linguistic variables in this study are defined as $\{\mathrm{NB}, \mathrm{NM}$, $\mathrm{Z}, \mathrm{PM}, \mathrm{PB}\}$, where NB means negative big, NM means negative medium, $\mathrm{Z}$ means zero, $\mathrm{PM}$ means positive medium and $\mathrm{PB}$ means positive big. The control strategy of the motor speed is presented in Figure 7.

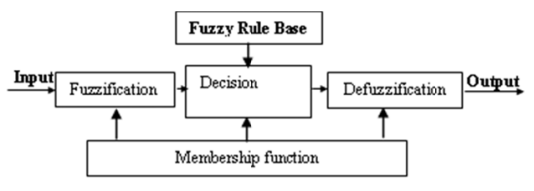

Fig. 5. Structure of fuzzy logic controller. 

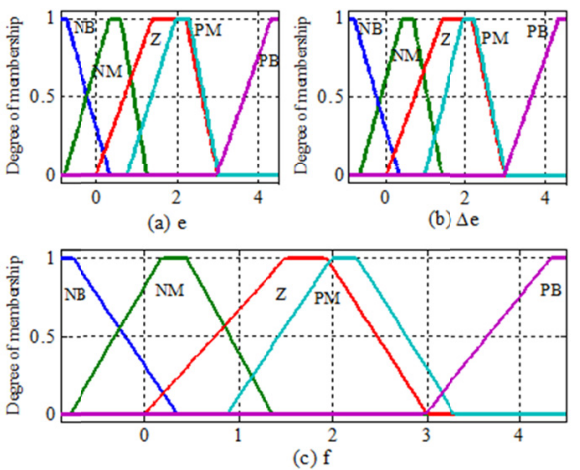

Fig. 6. Membership functions obtained from fuzzy

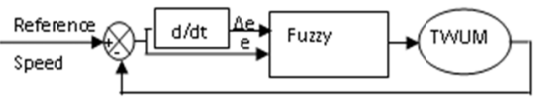

Fig. 7. Speed Control of TWUSM using logic fuzzy controller

\section{Simulation RESUltS AND DISCUSSION}

Speed response for loaded motor is analyzed for the considered TWUSM. The performance parameters such as settling time, steady state error, overshoot are obtained for FLC and compared to those obtained by PI controller. Simulation results of speed response are presented in order to validate the effectiveness of the proposed FLC for no load and loaded motor conditions. The parameters of the piezoelectric motor are: $570 \mathrm{~V}$ is excitation voltage's amplitude and $\pi / 2 \mathrm{rad}$ is the shift between the two excitations. The parameter values of the motor [17] used for the simulation are presented in Table II. Results have been obtained by keeping the reference speed equal to $45.5 \mathrm{rpm}$.

\section{A. No Loaded Motor Conditions}

The speed response characteristics of motor without load are presented in Figure 8 for the two controllers (Fuzzy and PI controllers). From the simulation results, analysis of the speed response of both PI and FLC controllers is given in Table III. From Table III, we can see that the FLC has better rise time and settling time than the PI controller. The settling time of the TWUSM without controllers is equal to $3.5 \mathrm{~ms}$ [23], we note that it has been reduced for the case of the controlled motor. To validate the robustness of the proposed FLC, the motor was tested for different loads at $t=2.5 \mathrm{~ms}$.

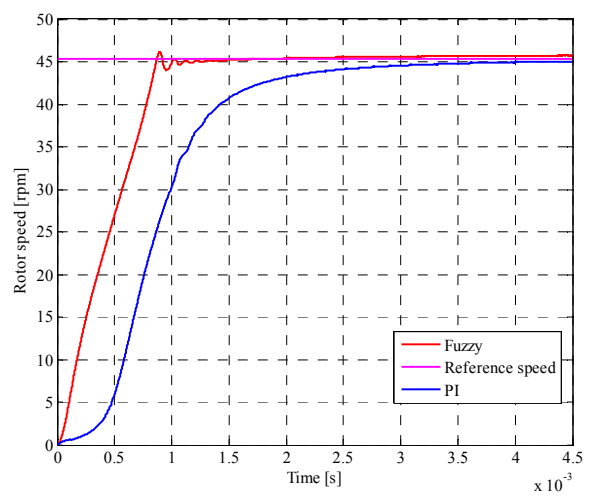

Fig. 8. Rotor speed without load
TABLE II. SIMULATION PARAMETERS [17]

\begin{tabular}{|c|c|}
\hline Resistances of entries & $\mathrm{Rp}_{1}=\mathrm{Rp}_{2}=5 \Omega$ \\
\hline Ceramics capacity & $\begin{array}{c}\mathrm{Cp}_{1}=7.8 \mathrm{e}^{-9} \mathrm{~F} \\
\mathrm{Cp}_{2}=7.87 \mathrm{e}^{-9} \mathrm{~F}\end{array}$ \\
\hline Capacity of stator & $\begin{array}{c}\mathrm{Cp}_{\mathrm{s1}}=0.42 \mathrm{e}^{-9} \mathrm{~F} \\
\mathrm{Cp}_{\mathrm{s} 2}=0.428 \cdot \mathrm{e}^{-9} \mathrm{~F}\end{array}$ \\
\hline Rotor Inertia & $\mathrm{J}_{\mathrm{R}}=3.34367 \mathrm{e}^{-0.004} \mathrm{kgm}^{2}$ \\
\hline Radius & $\mathrm{R}_{\mathrm{W}}=40.5 \mathrm{e}^{-3} \mathrm{~m}$ \\
\hline Effective mass & $\mathrm{M}_{\mathrm{eff}}=113.93 \cdot 10^{-3} \mathrm{Kg}$ \\
\hline Mass of rotor & $\mathrm{m}_{\mathrm{R}}=\left(\mathrm{m}_{\mathrm{eff}}+22.8+3\right) \cdot 1 \mathrm{e}^{-3} \mathrm{Kg}$ \\
\hline Rotor rigidity & $C_{R}=300 \mathrm{e}^{3} \mathrm{~N} / \mathrm{m}$ \\
\hline Rotor attenuation & $\mathrm{d}_{\mathrm{R}}=50 \mathrm{e}^{3} \mathrm{Ns} / \mathrm{m}$ \\
\hline Friction coefficient & $\mu=0.21$ \\
\hline $\begin{array}{c}\text { Distance between the surface } \\
\text { points of stator }\end{array}$ & $\alpha=4.5 \mathrm{e}^{-3} \mathrm{~m}$ \\
\hline Number of wave crests & $\mathrm{n}=11$ \\
\hline Frequency of resonance & $\omega_{r e s 1}=\omega_{r e s 2}=2 \pi \cdot 43.365 \cdot e^{3} \mathrm{~Hz}$ \\
\hline Wavelength & $\lambda=\frac{2 \cdot \pi \cdot R_{w}}{n} m$ \\
\hline Wave numbers & $\mathrm{k}=2 \pi / \lambda$ \\
\hline Contact zone rigidity & $\mathrm{C}_{\mathrm{N}}=8500 \mathrm{e}^{6} \mathrm{~N} / \mathrm{m}^{2}$ \\
\hline Antiresonance frequency & $\omega_{a n t 1}=\omega_{a n t 2}=2 \pi \cdot 43.425 \cdot e^{3} H z$ \\
\hline Modal mass of stator & $m=0.082 K g$ \\
\hline Transfer ratio & $\begin{array}{l}A_{1}=\left(m C p_{1}\left(\omega_{\text {ant } 1}\right)^{2}-\left(\omega_{\text {res } 1}\right)^{2}\right)^{1 / 2}\left(K g F s^{-2}\right)^{1 / 2} \\
A_{2}=\left(m C p_{2}\left(\omega_{\text {ant } 2}\right)^{2}-\left(\omega_{\text {res } 2}\right)^{2}\right)^{1 / 2}\left(K g F s^{-2}\right)^{1 / 2}\end{array}$ \\
\hline Stator rigidity & $\begin{array}{l}C_{S 1}=\left(\omega_{r e s 1}\right)^{2} \cdot m N / m \\
C_{S 2}=\left(\omega_{r e s 2}\right)^{2} \cdot m N / m\end{array}$ \\
\hline Disturbance factor & $\varepsilon_{1}=\varepsilon_{2}=0.02$ \\
\hline Damping ratios & $\mathrm{d}_{\mathrm{s} 1}=\mathrm{d}_{\mathrm{s} 2}=10 \mathrm{Ns} / \mathrm{m}$ \\
\hline
\end{tabular}

TABLE III. COMPARISON OF CONTROL SYSTEMS PERFORMANCE PARAMETERS

\begin{tabular}{|c|c|c|c|}
\hline Controller & Rise time (ms) & Peak time (ms) & Settling time (ms) \\
\hline PI & 1.000 & 4.5 & 2.500 \\
\hline Fuzzy & 0.73 & 0.893 & 1.200 \\
\hline
\end{tabular}

\section{B. The First Load, $1.5 \mathrm{Nm}$.}

From the response plots shown in Figure 9(a), in zoomed part $3.3 m s-3.8 m s$, the proposed FLC drive the TWUSM to track the reference speed. The controller's performances are resumed in the Table IV.

TABLE IV. COMPARISON OF CONTROL SYSTEMS PERFORMANCE PARAMETERS (LOADED MOTOR)

\begin{tabular}{|c|c|c|c|}
\hline Controller & Rise time (ms) & Peak Time (ms) & Settling time (ms) \\
\hline PI & 1.000 & 4.5 & 2.700 \\
\hline Fuzzy & 0.73 & 0.893 & 1.100 \\
\hline
\end{tabular}

\section{The Second Load, 1.6Nm.}

At this stage of study, we check the robustness of the proposed FLC against a load condition equal to $1.6 \mathrm{Nm}$. The simulation results are illustrated in Figure 9(b). We can note that the PI controller lose its performance in terms of tracking ability and only the FLC $\mathrm{H}_{\infty}$ can be resisting this parametric variation. 


\section{The Third Load $3.3 \mathrm{Nm}$}

The motor has been loaded with a big load larger than the torque that can be supported by the PI controller. From the results given in the Figure 9(c), we note that the FLC can drive, similar to the previous cases, the TWUSM to track the reference speed. In the range $t=2.5 \mathrm{~ms}-3 \mathrm{~ms}$, the motor speed decreases under the load effect and then it increases to reach the reference speed. Noting that for a large load, greater than $3.3 \mathrm{Nm}$, the TWUSM under FLC diverges. This phenomenon, called pull out phenomenon, has been signaled in the literature [24]. It is due especially to the variation of the resonance frequency. Finally, FLC is more robust than the PI controller and it presents low error. Therefore, it is well suited to this actuator type which can be employed for varying loads.
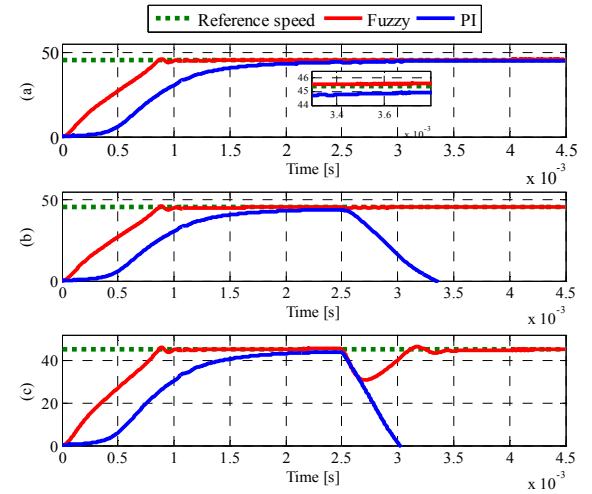

Fig. 9. Rotor speed, loaded motor a) $1.5 \mathrm{Nm}$, b) $1.6 \mathrm{Nm}$, c) $3.3 \mathrm{Nm}$

\section{SiMULATION RESULTS AND EXPERIMENTAL DATA VALIDATION}

To ensure the good operation of the TWUSM, the motor should be driven with the antiresonance frequency to reach the maximum of its efficiency [25]. To determine the antiresonance frequency of the TWUSM AWM90-X, the stator parameters were calculated with finite elemet method (FEM), obtained from the recorded admittance curve of the stator. The admittance curve of the free-vibrating stator was recorded with the impedance analyzer with a step size of $10 \mathrm{~Hz}$. Figure 10 shows the resulting measured curve. From Figure 10, the antiresonance frequency is equal to $43.425 \mathrm{kHz}$ [25].

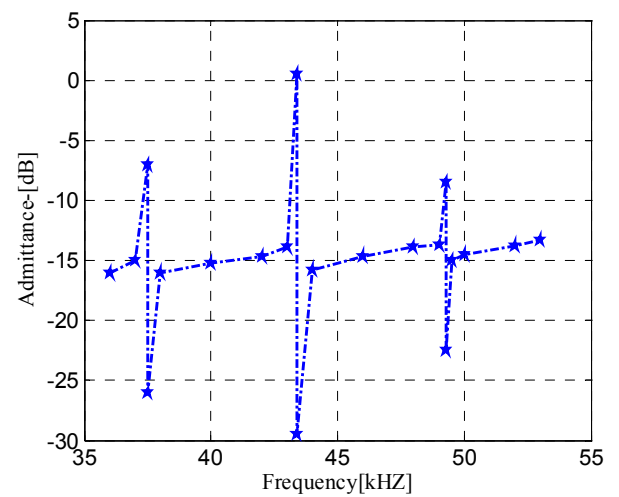

Fig. 10. Recorded admittance curve of AWM90-X stator
Regarding the proposed TWUSM model, we can note that it was validated in our previous work [17] without control speed. In fact, the simulation frequency of the proposed model was equal to $43.425 \mathrm{kHz}$ which is the same with the one obtained in experimental validation [25]. Moreover, to validate the proposed controller, the frequency output of the FLC is illustrated in Figure 11. Hence, the simulation frequency has been found equal to $44.6 \mathrm{kHz}$, which is closer to the experimental antiresonance frequency $(43.425 \mathrm{kHz})$. This result validates the efficiency of the FLC.

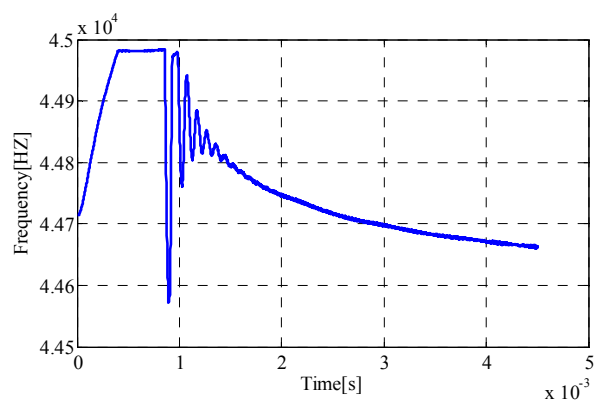

Fig. 11. Frequency output of the FLC

\section{CONCLUSION}

In this paper, the frequency speed control of the TWUSM, type Daimler Benz AWM90-X, has been studied. The design of FLC and PI controllers has been presented and discussed. To illustrate the efficiency of the proposed controllers to drive the TWUSM to track perfectly the reference speed, thorough simulations were performed. The obtained results have revealed that the FLC controller performs better than the PI controller with very good tracking performance, namely low rise time, low settling time and high steady state accuracy. Likewise, the FLC controller seems more robust that the PI controller against load variations. Finally, the frequency output of the FLC has been validated with experimental measurements of the TWUSM AWM90-X.

\section{REFERENCES}

[1] D. Zhang, S. Wang, J. Xiu, "Piezoelectric parametric effects on wave vibration and contact mechanics of traveling wave ultrasonic motor", Ultrasonics, Vol. 81, pp. 11-126,2017

[2] Y. Wang, W. Huang, "A piezoelectric motor with two projections using two orthogonal flexural vibration modes", Sensors and Actuators A: Physical, Vol. 250, pp. 170-176, 2016

[3] F. R. M. Romlay, W. A. W. Yusoff, K. A. M. Piah, "Increasing the efficiency of traveling wave ultrasonic motor by modifying the stator geometry", Ultrasonics, Vol. 64, pp. 177-185, 2016

[4] G. Bal, E. Bekiroglu, "Servo speed control of traveling -wave ultrasonic motor using digital signal processor", Sensor and Actuators A: Physical, Vol. 109, No. 3, pp. 212-219, 2004

[5] A. Gencer, "A Comparative Speed/Position Control Technique Based Fuzzy Logic Control for Travelling Wave Ultrasonic Motor", 7th International Conference on Electronics, Computers and Artificial Intelligence (ECAI), Bucharest, Romania, June 25-27, 2015

[6] T. Senjyu, M. Nakamura, U. Urasaki, H. Sekine, T. Funabashi, "Mathematical Model of Ultrasonic Motors for Speed Control", Electric Power Components and Systems, Vol. 36, No. 6, pp. 637-648, 2008

[7] J. Shi, B. Liu, "Optimum Efficiency Control of Traveling-Wave Ultrasonic Motor System", IEEE Transaction on Industrial Electronics, Vol. 58, No. 10, pp. 4822-4829, 2011 
[8] K. T. Chau, S. W. Chung, C. C. Chan, "Neuro-fuzzy speed tracking control of traveling-wave ultrasonic motor drives using direct pulsewidth modulation", IEEE Transactions on Industry Applications, Vol. 39, No. 4, pp. 1061-1069, 2003

[9] K. T. Chau, S. W. Chung, "Servo position control of ultrasonic motors using fuzzy neural network", Electric Power Components and Systems, Vol. 29, No. 3, pp. 229-246, 2001

[10] G. Bal, E. Bekiroglu, S. Demirbas, I. Colak, "Fuzzy logic based DSP controlled servo position control for ultrasonic motor", Energy Conversion and Management, Vol. 45, No. 20, pp. 3139-3153, 2004

[11] T. Senjyu, S. Yokoda, K. Uezato, "Speed control of ultrasonic motors using fuzzy neural network", Journal of Intelligent and Fuzzy Systems, Vol. 8, No. 2, pp. 135-146, 2000

[12] T. Senjyu, T. Yoshida, K. Uezato, T. Funabashi, "Position control of ultrasonic motors using adaptive backstepping control and dead-zone compensation with fuzzy inference", IEEE International Conference on Industrial Technology, Bankok, Thailand, pp. 560-565, December 1114,2002

[13] M. Brahim, I. Bahri, Y. Bernard, "Real time implementation of Hinfinity and RST motion control of rotary traveling wave ultrasonic motor", Mechatronics, Vol. 44, pp. 14-23, 2017

[14] S. Jingzhuon, L. Yu, H. Jingtao, X. Meiyu, Z. Juwei, Z. Lei, "Novel intelligent PID Control of travelling wave ultrasonic motor", ISA Transactions, Vol. 53, No. 5, pp. 1670-1679, 2014

[15] F. Z. Kebbab, Z. Boumous, S. Belkhiat, "Traveling Wave Ultrasonic Motor Type Daimler-Ben AWM90-X: Modeling and Simulation Mechanical Characteristics", Journal of Electrical Systems, Vol. 1, pp. 24-29, 2009

[16] F. Z. Kebbab, Z. Boumous, S. Belkhiat, "Rotary Ultrasonic Motors: Daimler-Benz AWM 90-X TWUSM motor, Experimental and Simulation mechanical characteristics", Journal of Electrical Systems, Vol. 5, No. 4, 2009

[17] Z. Boumous, S. Belkhiat, F. Z. Kebbab, "Effect of shearing deformation on the transient response of a traveling wave ultrasonic motor", Sensors and Actuators A: Physical, Vol. 150, No. 2, pp. 243-250, 2009

[18] K. Premkumar, B. V. Manikandan, "Adaptive Neuro-Fuzzy Inference System based speed controller for brushless DC motor", Neurocomputing, Vol. 138, pp. 260-270, 2014

[19] A. Prabaharan. E. Balamurugan, "Speed Control of Switched Reluctance Motor Using ANFIS and GA", International Journal of Advanced Research in Electrical, Electronics and Instrumentation Engineering, Vol. 5, No. 7, pp. 152-158, 2016

[20] V. M. Varatharaju, B. L. Mathur, "Adaptive Neuro-Fuzzy speed Controller for husteresis curent controlled PMBLDC motor derive", International Journal of Advances in Engineering \& Technology, Vol. 1, No. 4, pp. 212-223, 2011

[21] H. Chaudhary, S. Khatoon, R. Singh, "ANFIS Based Speed Control of DC Motor", 2nd International Innovative Applications of Computational Intelligence on Power, Energy and Controls with their Impact on Humanity (CIPECH), Ghaziabad, India, November 18-19, 2016

[22] N. Muruganantam, S. Palani, “Adaptive Neuro-Fuzzy Inference system based controller for high performance BLDC motor using soft switching inverter", Journal of Theoretical and Applied Information Technology, Vol. 49, No. 3, 2013

[23] E. Bekiroglu, "Microcontroller-based full control of ultrasonic motor with frequency and voltage adjusting", Sensors and Actuators A: Physical, Vol. 141, No. 1, pp. 151-159, 2008

[24] B. Matteo, Modelisation et commande du moteur piezoelectrique a onde progressive, PhD Thesis, Ecole Polytechnique Federale de Lausanne, 2005 (in French)

[25] G. Kandare, J. Wallaschek, "Derivation and validation of a mathematical model for travelling wave ultrasonic motors", Smart Materials and Structures, Vol. 11, No. 4, pp. 565-574, 2002

\section{AUTHORS PROFILE}

Fatima Zohra Kebbab was born in Algeria in 1982. She received an Electrical Engineering degree and a Master's degree from the Electrical Engineering Department, Ferhat Abbas University, Setif 1, Algeria, in 2003 and 2007, respectively. She is an assistant professor in the Electrical Engineering Department, Ferhat Abbas University, Setif 1, Algeria. She works on the traveling wave motor.

Djamel Eddine Chouaib Belkhiat was born in Algeria. He is an associate professor in the Department of Physics at the Ferhat Abbas University, Setif 1 , Algeria, where he is also a member of DAC HR Laboratory. He earned his Bachelor of Engineering degree in Electrical Engineering at Ferhat Abbas University, Setif 1, Algeria, Master's degree in Automatic Control from the University of Poitiers, France, and $\mathrm{PhD}$ degree in Automatic Control from the University of Reims Champagne Ardenne, France, in 2007, 2008, and 2011, respectively. His research interests lie in the area of monitoring and diagnosis of dynamic systems. He has published several research papers in scientific journals, international conferences, and book chapters.

Dalel Jabri was born in Tunisia. She is an associate professor in the Electrical Engineering Department at the Ferhat Abbas University, Setif 1, Algeria, where she is also a member of DAC HR Laboratory. She earned her Bachelor of Engineering degree in Electrical Engineering in 2006, her Master's degree in Automatic Control in 2007 at National Engineering School of Gabes, Tunisia, and her $\mathrm{PhD}$ degree in Automatic Control at the University of Reims Champagne Ardenne, France and the University of Gabes at 2011. Her research interests lie in the area of robust control of nonlinear systems. She has published several research papers in scientific journals, international conferences, and book chapters.

Saad Belkhiat was born in Algeria. He received an Electronic Engineering degree from Polytechnic School of Algiers, Algeria, in 1979. He has worked as an engineer in the control and automatic departments in the production industry and as an engineering professor in the Department of Electronics, Setif, Algeria. He received an MPh degree from the Electronics Department, and PhD degree in Physics, from University of Setif in 2001. He is fullprofessor in the Electrical Engineering Department at the Ferhat Abbas University, Setif 1, Algeria. His research interests include electrical engineering materials and their applications such as piezoelectric materials, dielectric and surface science. 